\title{
Early marker of motor developmental delay in preterm infants
}

\author{
Rabindran', Gedam D. $S^{2}$ \\ ${ }^{1}$ Dr. Rabindran, Consultant, Neonatologist, Billroth Hospital, Chennai, India, ${ }^{2}$ Dr. D. Sharad Gedam, Professor of \\ Paediatrics, R. K. D. F. Medical College \& Associated S. R. K. University, Bhopal, MP, India.
}

Address for Correspondence: Dr. Rabindran, E- mail: rabindranindia@yahoo.co.in

\begin{abstract}
Early markers of motor delay which have been studied include antenatal characteristics of mother and perinatal variables likeheart rate variability, responsiveness to stimulation, motor function, behavioral state and infant size.
\end{abstract}

Keywords: Developmental delay, General movements, Preterm infants.

Nearly $10 \%$ of preterm babies develop severe motor impairments [1]. About $50 \%$ of very low birth weight preterm babies $(\leq 1,500 \mathrm{~g})$ and extremely low birth weight preterm babies $(\leq 1,000 \mathrm{~g})$ develop neuromotor disorders [2]. Mild motor delay occurs 3-4 times more in preterm babies as compared to term babies. Nearly $47 \%$ of very pretermshave mildly delayed scores on Gross Motor Subscale of the Bayley III at 8-12 months corrected ageand $29 \%$ score 1SD below mean on gross motor and $34 \%$ on fine motor scale of Bayley III at 2.5 years corrected age [3].

There are various screening tests for early diagnosis of motor abnormalities like DENVER II, Alberta Infant Motor Scale, Movement Assessment of Infants, Test of Infant Motor Performance, General Movements \& Bayley II and III Scale.However symptoms of motor impairment like abnormalities of muscle tone, control, primitive reflexes, postural reactions and lack of inhibition of involuntary movement become evident only as the preterm baby matures to about 18- 24 months of corrected gestational age [4]. Early markers of motor delay which have been studied include antenatal characteristics of mother and perinatal variables likeheart rate variability, responsiveness to stimulation, motor function, behavioral state and infant size. With the recent four-dimensional ultrasonography analysis of in uterofetal behaviour is possible as early as first trimester. Cranial ultrasound can detect germinal matrix and intraventricular hemorrhage, ventricular dilation and periventricular leukomalacia which are associated with motor impairment. MRI is useful to differentiate white and gray matter injuries with greater sensitivity whereas Diffusion tensor magnetic resonance imaging can map white matter pathways. There is a high incidence of abnormal muscle tone observed among premature infants upto 18 months of age. Early truncal tone abnormalities are associated with a worse developmental outcome. Infants with Truncal hypertonicity and truncal or lower extremity hypotonicity at 3 months was associated with significantly poor Bayley motor and mental scores at 18 months [5]. Atypical early head, arm, leg, or trunk movements are red flag signs for motor developmental disorders.

Irritability, abnormal finger posture, spontaneous Babinski reflex, weakness of lower limbs, transient tone abnormalities and delay in achieving motor milestonesare some of the neurological signs among high-risk preterm infants later associated with neuromotor delay. Without any sensory input, fetal and neonatal nervous system generates motor patterns like startles, twitches, stretching, yawning known as general movements. Prechtl et al., introduced a new approach to neurological evaluation based on spontaneous motor activity, rather than reflexes and evoked responses [6]. Abnormal General movements include hypokinesis, poor repertoire, abnormal or absent fidgety movements, chaotic and cramped synchronized General movements. Predominant cramped movements has $100 \%$ sensitivity and around 93\% specificity for predicting motor delay [7]. Spontaneous activity has been found to be more sensitive of brain dysfunction than reactivity to sensory stimuli. Visual gestalt perception is a new 
technology to detect alterations in the movementsand absent fidgety movements are associated with severe motor deficits. Background electroencephalograms and monitoring maturation of certain rhythmic theta activity termed "temporal sawtooth" has been shown to identify neuromotor abnormalities in preterm infants. A novel method of neonatal motor assessment has been developed by analysis of intraoral sucking pressures and infant's control while feeding and preterm infants who sucked irregularly had delayed motor development [8]. A recent study has shown that babies who were more fussy in prone position had significantly higher rate of motor delays than infants who spent longer in prone which could be used as a marker for the early identification of motor delays [9]. Studies have shown that poor ability to lift head in prone and align head with body during pull-to-sit at term and 12 weeks CGA were associated with motor delays at one year [10] and Kinematic measurements of head control in early infancy help as an objective quantitative marker of future motor impairment. In this issue Diwanmal SB studied to determine the effectiveness of Test of Infant Motor Performance (TIMP) in detecting motor developmental delay in preterm infants. TIMP and Alberta Infant Motor Scale (AIMS) are equally useful in the assessment of infant motor performance at 4 months of corrected age [11].

Funding: Nil, Conflict of interest: None initiated, Perission from IRB: Yes

\section{References}

1.Johnson, S., Evans, T. A., Draper, E. S., Field, D. J., Manktelow B. N., Marlow, N., et al. Neurodevelopmental outcomes following late and moderate prematurity: a population-based cohort study. Arch Dis Child Fetal Neonatal Ed 2015;100: F301-F308. doi:10.1136/archdischild-2014-307684

2. Rugolo LM. Growth and developmental outcomes of the extremely preterm infant. J Pediatr (Rio J). 2005 Mar;81(1 Suppl):S101-10.

3. Greene MM1, Patra K, Nelson MN, Silvestri JM. Evaluating preterm infants with the Bayley-III: patterns and correlates of development. Res Dev
Disabil.2012Nov-Dec;33(6):1948-56.doi: 10.1016/j. ridd. 2012. 05.024.

4. Blauw-Hospers $\mathrm{CH}$, Hadders-Algra M. A systematic review of the effects of early intervention on motor development. Dev Med Child Neurol 2005; 47: 421-432. doi:10.1111/j.1469-8749.2005. tb01165.x

5.Michael K. Georgieff, Judy C. Bernbaum, Marsha Hoffman-Williamson, Andrea Daft. Abnormal Truncal Muscle Tone as a Useful Early Marker for Developmental Delay in Low Birth Weight Infants. Pediatrics, May 1986, 77(5).

6. Prechtl HF Qualitative changes of spontaneous movements in fetus and preterm infant are a marker of neurological dysfunction. Early Hum Dev. 1990;23151-158.doi.org/10.1016/0378-3782(90)

90011-7

7. Yuge M, Marschik PB, Nakajima Y, Yamori Y, Kanda T, Hirota H, Yoshida N, Einspieler C. Movements and postures of infants aged 3 to 5 months: to what extent is their optimality related to perinatal events and to the neurological outcome? Early Hum Dev. 2011 Mar;87(3):231-7. doi: 10.1016/j.earlhumdev.2010.12.046.

8. Craig, C., Grealy, MnLee, D. Detecting motor abnormalities in preterm infants; Exp Brain Res (2000) 131:359-365. DOI 10.1007/s002219900227.

9. Cross J, Eastman D, Brovender S, Ward MJ. Intolerance to Prone Positioning as a Clinical Marker of Motor Delay in Infants. J Pediatr Child Care. 2017;3(1): 06.

10.Coker-Bolt. P, Woodbury. M, Perkel. J, Moreau. N, Hope. K, Ramakrishnan. V, Mulvihill. D, Jenkins. D. Identifying premature infant at high and low risk for motor delays using motor performance testing and MRS.Journal of Pediatric Rehabilitation Medicine: An Interdisciplinary Approach 7 (2014) 219-232 219DOI 10.3233/PRM-140291.

11. Diwanmal SB, Dharmayat SR., Biradi MK, Vanaki RN., Pol RR, Yelamali BC. Predicting the effectiveness of Test of Infant Motor Performance as an early marker of motor development delay in preterm infants. IntJ PediatrRes. 2017;4(09):572579.doi:10. 17511/ijpr.2017.09.06.

How to cite this article?

Rabindran, Gedam D. S. Early marker of motor developmental delay in preterm infants. J PediatrRes. 2017; 4(09):544-545.doi:10. 17511/ijpr.2017.i09.01. 